\title{
La vinculación como técnica de enseñanza y aprendizaje del Derecho. Derechos Humanos, universidad y Poder Legislativo ${ }^{1}$
}

\section{Linking university and legislature as teaching approach for learning law. Human rights, university and the legislative}

Resumen: México se encuentra en la implementación de un grupo de importantes reformas que han cambiado paradigmas en el sistema jurídico nacional. Sin embargo, los programas y métodos de estudio en las universidades y facultades de derecho no han avanzado a la misma velocidad que los cambios al sistema jurídico. Para lograr abogados profesionales capaces de enfrentar problemas contemporáneos, se requiere de herramientas de estudio y enseñanza que permitan estudiar un derecho actualizado y dinámico. El objetivo del trabajo es la propuesta de un método de enseñanza y aprendizaje del derecho mediante la vinculación entre universidades y poder legislativo, que coadyuve a los estudiantes en derecho a su actualización de la normativa vigente, a comprender la naturaleza dinámica del derecho como objeto de estudio; y al mismo tiempo permita aportar creatividad y sustento a la dogmática jurídica, a las modificaciones legales, para lograr unidad y congruencia en el sistema y que respete y fortalezca los principios de universalidad, interdependencia, indivisibilidad y progresividad de los Derechos Humanos.

Palabras clave: Enseñanza, aprendizaje, Derecho, Poder Legislativo, Derechos Humanos, universidad.

\begin{abstract}
Mexico is currently carrying out the implementation of a set of major reforms that are changing the paradigms that rule the national legal system. Nonetheless, programs and methods of study in law schools have not progressed at the same rate as changes to the legal system. In order to have professional lawyers capable of tackling contemporary issues, Mexican universities will require updating teaching tools and methods for the study of an updated and dynamic law. The aim of this paper is to propose a method of teaching and learning law by linking universities with the legislature. This idea would contribute to understand the dynamic nature of law as object study and would allow achieving unity and coherence in the system, and to strengthening the principles of universality, interdependence, indivisibility and progressiveness of human rights.
\end{abstract}

Key Words: Teaching, learning, law, legislature, human rights, university.

\footnotetext{
${ }^{1}$ La hipótesis de esta investigación se expuso en el Segundo Congreso Internacional de Pedagogía Universitaria y Didáctica del Derecho, que tuvo lugar en el Instituto de Investigaciones Jurídicas (IIJ) de la Universidad Nacional Autónoma de México (UNAM), el 6 de noviembre de 2014, organizado por el IIJ de la UNAM y la Facultad de Derecho de la Universidad de Chile.

${ }^{2}$ Licenciada en Derecho, con Mención Honorífica por la Facultad de Derecho de la Universidad Nacional Autónoma de México (UNAM); con Especialidad en Justicia Administrativa por el Tribunal Federal de Justicia Fiscal y Administrativa y estudios de Maestría por la UNAM. Ha sido parte del Sistema Nacional de Investigación (SNI-CONACyT) como asistente de investigación y becaria del Instituto de Investigaciones Jurídicas de la UNAM. Formó parte del Sistema de Intercambio Alemán (DAAD) de la Universidad de Erfurt, Alemania. Investigadora visitante en la Universidad Pablo de Olavide en Sevilla, España durante 2012. Actualmente lleva a cabo estudios de Posgrado en Derecho Parlamentario en la Universidad Autónoma del Estado de México y labora como asesor jurídico en temas legislativo-parlamentarios en el Senado de la República. ivonne.dimaz@gmail.com.
} 


\section{Introducción}

México se encuentra en un proceso de implementación de importantes reformas en materia de justicia penal, derechos humanos, control de convencionalidad y mecanismos alternativos de solución de controversias. Este proceso se inició en el 2008 con reformas constitucionales que han motivado a su vez, cambios a leyes reglamentarias de la constitución, leyes federales e incluso el diseño de nuevos ordenamientos jurídicos (leyes y códigos).

Es de reconocer que a través de estas reformas, por lo menos en su primera etapa de diseño normativo, México ha dado importantes pasos en el reconocimiento, ampliación y desarrollo de instrumentos jurídicos de protección a derechos humanos. Sin embargo y lamentablemente, en el proceso de implementación de esta gran reforma, se incluyeron a nivel constitucional, figuras contradictorias entre sí, que se han extendido a otros cuerpos normativos de jerarquía inferior, que relativizan los avances del Estado mexicano, en el cumplimiento de compromisos respecto al Derecho Internacional de los Derechos Humanos.

Desde el ámbito académico surge otra complicación. No obstante que este proceso de reforma al sistema jurídico nacional inició siete años atrás, las universidades públicas y en específico las facultades de derecho en nuestro país, han presentado complicaciones para mantener actualizados sus planes de estudios.

Por ejemplo, en la Universidad Nacional Autónoma de México, la evaluación de los contenidos en el currículo de los planes de estudio se regula por los artículo 14 y 15 del Reglamento General para la Presentación, Aprobación y Modificación de Planes de Estudio (RGPAMPE modificados por última vez el 20 de junio de 2003) y por los artículos 19, 20 y 21 del Marco Institucional de Docencia (MID reformado por última vez el 30 de septiembre de 2003). La decisión final sobre los cambios a los planes de estudio en estructura o contenido, la tomará el Consejo Técnico de la Facultad de Derecho, encargado de comunicarlos a la Dirección General de Administración Escolar (DGAE) y al Consejo Académico del Área de las Ciencias Sociales (CAACS). Tendrán que pasar seis años forzosamente para realizar nuevas modificaciones y diagnóstico de los cambios.

Como podemos ver el proceso es dilatado, solo la evaluación demora por lo menos seis años. Mientras tanto, en la esfera fáctica, en periodos muy breves se pueden generar reformas importantes a las estructuras del sistema jurídico nacional. ${ }^{3}$ Lo anterior, representa un reto adicional. No es viable las reformas constantes a los planes de estudio para incluir cada cambio generado desde el legislativo.

Una desvinculación entre la Universidad y el Poder Legislativo se traduce en una desvinculación e incluso, ausencia de dogmática, filosofía y axiología jurídica en la

\footnotetext{
${ }^{3}$ Para ejemplificar esto, en México, durante los tres primeros años de una nueva Administración del Ejecutivo Federal, el Congreso de la Unión aprobó 11 reformas estructurales que representaron cambios a la Constitución así como a las instituciones. Estos cambios implican modificaciones de fondo en materia de energía, competencia económica, telecomunicaciones y radiodifusión, hacendaria, financiera, laboral, educativa, una Nueva Ley de Amparo, un Código Nacional de Procedimientos Penales, reforma político-electoral, así como en materia de transparencia.
} 
creación de normas jurídicas. Esto representa riesgos en la consolidación de un Estado democrático y sobre todo representa riesgos en el respeto a los derechos humanos por parte de la autoridad, quien puede modificar el ordenamiento legal disminuyendo o eliminando con intención o por ignorancia - derechos fundamentales de los ciudadanos.

El escenario expuesto nos plantea retos significativos: ¿cómo formar estudiantes que cuenten con las herramientas necesarias para analizar un objeto tan dinámico como lo es el derecho?, ¿cómo mantener actualizados los programas de estudio en las facultades de derecho ante una dinámica jurídico-social permanentemente mutable?, ¿cómo lograr que estudiantes de derecho que aprenden en las universidades paradigmas superados por la realidad, se conviertan en profesionales al salir de ellas?, ¿cómo enseñar y aprender un derecho actualizado?, ¿cómo puede ayudar la academia a evitar dicotomías en el sistema jurídico?, ¿cómo puede la enseñanza del derecho beneficiar la protección de los derechos humanos?

La hipótesis de la presente investigación es la siguiente:

- En México existe una desvinculación entre Poder legislativo $\Leftrightarrow$ Universidad, que representa una problemática para la enseñanza y aprendizaje del derecho, y repercute negativamente en el diseño de mecanismos jurídicos para la protección de los derechos humanos.

Esta situación de desvinculación coincide con la implementación de un conjunto de reformas que modifican paradigmas jurídicos.

El objetivo es proponer un modelo de enseñanza-aprendizaje del derecho mediante el cual:

- Los estudiantes se mantengan actualizados respecto a los cambios jurídicos.

- Se fortalezca un Estado de Derecho, donde investigaciones académicas, dogmática y filosofía jurídica, sean insumo en la creación de leyes.

- Se elimine del sistema jurídico nacional figuras contradictorias, algunas de las cuales se contraponen a la vigencia de los derechos humanos.

- La protección de la dignidad humana - fundamento de los derechos humanos - sea el concepto base que dé congruencia al sistema jurídico nacional.

Para lograr lo anterior, el modelo propuesto tendrá como eje, la vinculación de las universidades y facultades de derecho, con el poder legislativo mexicano.

\section{Proceso de reformas al sistema jurídico mexicano: un cambio de paradigmas}

México se adhirió a la Convención Americana sobre Derechos Humanos el 24 de marzo de 1981, y reconoció la competencia contenciosa de la Corte Interamericana de Derechos Humanos el 16 de diciembre de 1998 mediante declaración unilateral de voluntad, publicada en el Diario Oficial de la Federación (DOF) el 24 de febrero de 1999. Estos momentos en la historia son muy importantes para el desarrollo de la teoría de los derechos humanos, su protección y cumplimiento en el país.

Después de esto, identificamos dos momentos clave en la evolución del sistema jurídico mexicano, considerados así, por el cambio de paradigmas que representan. 
El primer momento es el 18 de junio de 2008 cuando se publicó en el DOF una reforma que modificó 10 artículos constitucionales y contó con 11 artículos transitorios. Los cambios representaron modificaciones al sistema de seguridad pública, a la procuración de justicia penal, y al modelo de ejecución de sanciones penales. Entre los objetivos de la reforma se estableció el lograr un sistema penal con igualdad entre las partes, donde se reconozcan y protejan plenamente los derechos humanos. Lo más representativo es el cambio de un sistema penal de corte mixto a uno de corte oral-adversarial, la inclusión de la metodología de los juicios orales y el reconocimiento de mecanismos alternativos de solución de controversiales. El discurso con el que se promocionó esta reforma fue el de consolidar al Estado mexicano como un Estado garantista.

El segundo momento clave lo representa la reforma constitucional del 11 de junio de 2011. Mediante las modificaciones constitucionales, se lograron cambios profundos al sistema jurídico nacional en materia de derechos humanos. Destacamos los siguientes:

- Se modifica el verbo "otorga" por "reconoce". Esta modificación tiene una trascendencia sin precedente. Significa todo un cambio en la filosofía del derecho, toda vez que se establece el tránsito de un positivismo a un iusnaturalismo. El Estado no otorga derechos humanos, estos se fundamentan en la esencia misma de la persona y se obliga al Estado a reconocerlos.

- Los tratados internacionales en materia de derechos humanos jerárquicamente se encuentran al mismo nivel que la Constitución Federal, esto significa que las autoridades deben favorecer en todo momento, la protección más amplia a la persona (principio pro persona).

- Establece la obligación del Estado mexicano, en todos sus niveles de gobierno, de promover, respetar, proteger y garantizar los derechos humanos, respetando los principios de universalidad, interdependencia, indivisibilidad y progresividad.

En los siete años posteriores al 2008, México continuó con importantes reformas. Todas han representado un cambio profundo de paradigmas histórico jurídicos en el sistema de impartición de justicia nacional. Hoy en día México se encuentra en proceso de implementación de estos cambios.

Principales cambios al sistema jurídico mexicano en materia de justicia 2008-2015

\begin{tabular}{|c|c|l|}
\hline Fecha & Materia & \multicolumn{1}{c|}{ Síntesis } \\
\hline $\begin{array}{c}18 \mathrm{de} \\
\text { junio } \\
2008\end{array}$ & $\begin{array}{c}\text { Reforma } \\
\text { constitucional } \\
\text { Seguridad y } \\
\text { justicia penal }\end{array}$ & $\begin{array}{l}\text { Establece la oralidad (juicios orales) en el proceso penal, } \\
\text { crea la figura del juez de ejecución de sanciones penales, } \\
\text { reconoce constitucionalmente la presunción de inocencia, } \\
\text { asigna un nuevo reparto de responsabilidades entre los } \\
\text { actores en el proceso penal, establece los mecanismos } \\
\text { alternativos de solución de controversias, reconoce un } \\
\text { régimen de excepción para la delincuencia organizada. }\end{array}$ \\
\hline
\end{tabular}




\begin{tabular}{|c|c|c|}
\hline $\begin{array}{c}6 \text { de junio } \\
\text { de } 2011\end{array}$ & $\begin{array}{c}\text { Reformas } \\
\text { constitucionales } \\
\text { Derechos } \\
\text { humanos }\end{array}$ & 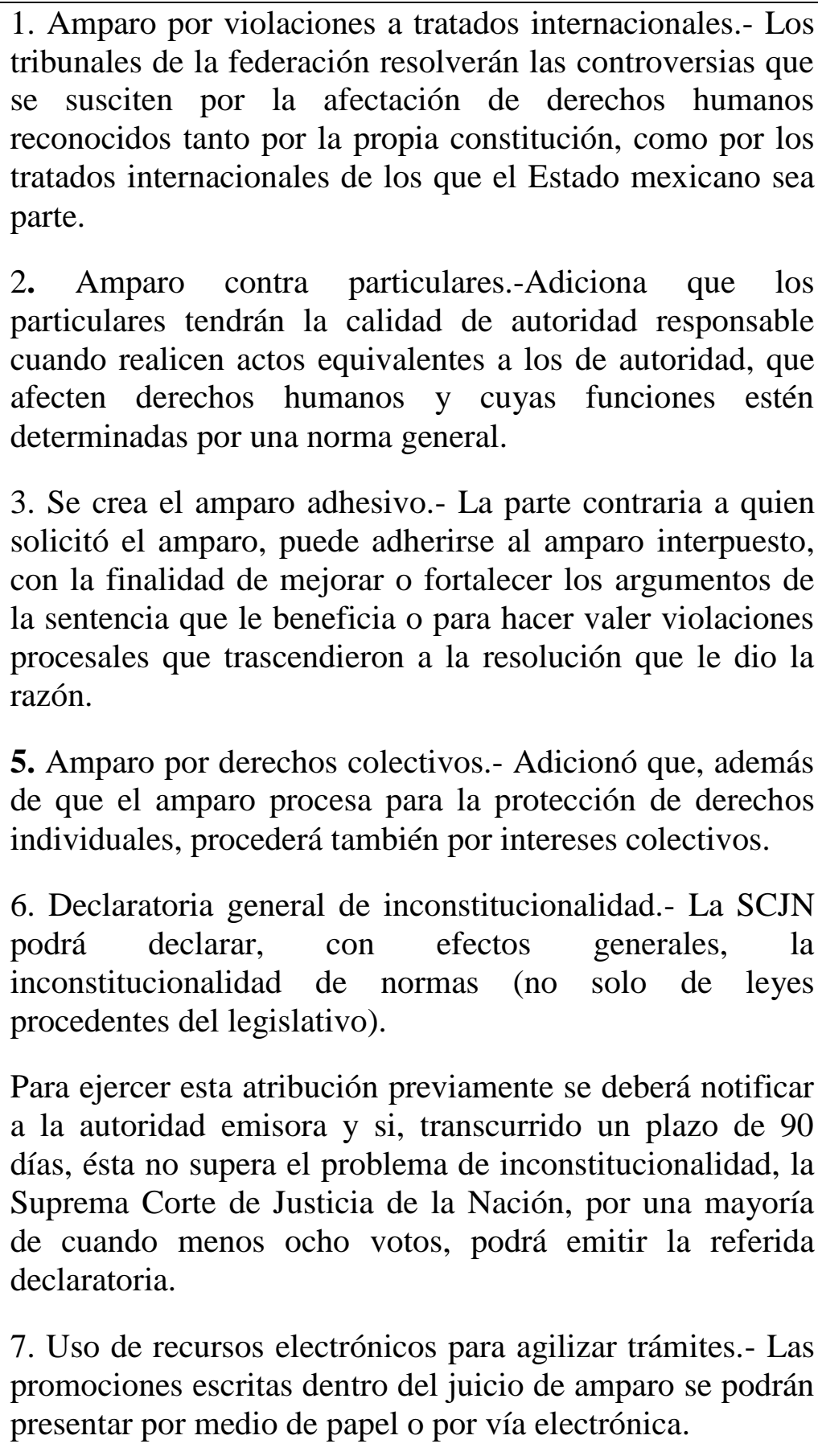 \\
\hline $\begin{array}{l}10 \mathrm{de} \\
\text { junio, } \\
2011\end{array}$ & $\begin{array}{c}\text { Reformas } \\
\text { constitucionales } \\
\text { Ley de Amparo }\end{array}$ & $\begin{array}{l}\text { 1. Denominación.- A partir de la reforma se llama "De los } \\
\text { derechos humanos y sus garantías", dejando atrás la } \\
\text { denominación de garantías individuales. La expresión } \\
\text { derechos humanos es mucho más moderna y es la que se } \\
\text { suele utilizar en el ámbito del derecho internacional. } \\
\text { 2. Reconocimiento de DH.- Cambia la palabra "otorgar" } \\
\text { por "reconocer" los derechos humanos de todas las } \\
\text { personas. Esto cambia la idea de que los derechos son }\end{array}$ \\
\hline
\end{tabular}




\begin{tabular}{|c|c|c|}
\hline & & 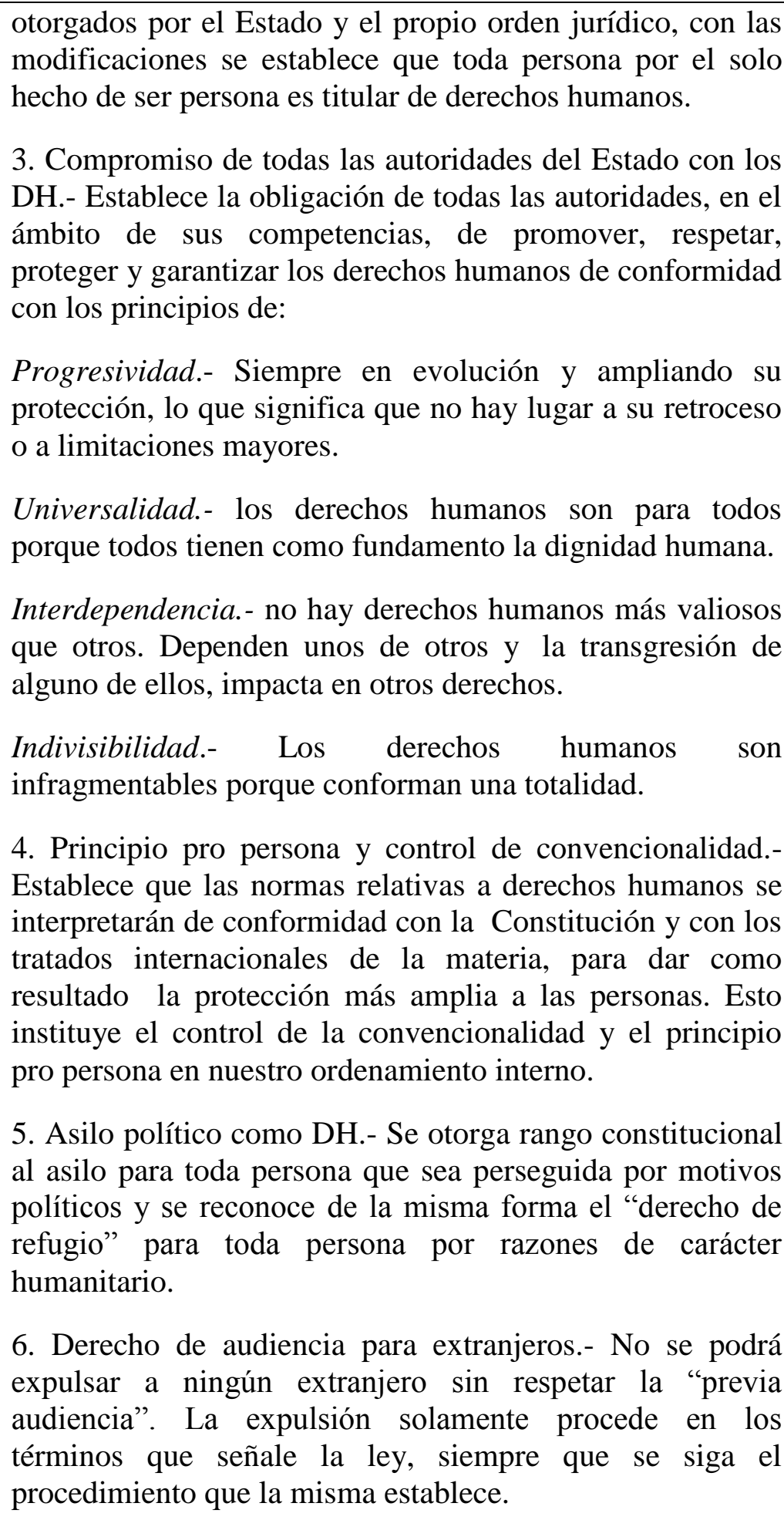 \\
\hline $\begin{array}{l}2 \text { de abril, } \\
2013\end{array}$ & $\begin{array}{l}\text { Ley } \\
\text { Reglamentaria } \\
\text { de la } \\
\text { Constitución }\end{array}$ & $\begin{array}{l}\text { Se publica la Nueva Ley de Amparo. Su finalidad es hacer } \\
\text { operativa la reforma constitucional del } 6 \text { de junio de } 2011 \text { y } \\
\text { el funcionamiento de las figuras jurídicas creadas. }\end{array}$ \\
\hline
\end{tabular}




\begin{tabular}{|c|c|c|}
\hline & Amparo & \\
\hline $\begin{array}{l}8 \text { de } \\
\text { octubre, } \\
2013\end{array}$ & $\begin{array}{c}\text { Reforma } \\
\text { constitucional } \\
\text { Facultades del } \\
\text { Congreso } \\
\text { Federal }\end{array}$ & $\begin{array}{l}\text { Se faculta al Congreso Federal para expedir legislación } \\
\text { única en materia procedimental penal, mecanismos } \\
\text { alternativos y ejecución de penas. }\end{array}$ \\
\hline $\begin{array}{l}5 \text { de } \\
\text { marzo, } \\
2014\end{array}$ & $\begin{array}{l}\text { Código } \\
\text { Nacional de } \\
\text { Procedimientos } \\
\text { Penales }\end{array}$ & $\begin{array}{l}\text { Establece en un solo ordenamiento jurídico las } \\
\text { disposiciones del proceso penal. Previo a él, existía un } \\
\text { código procedimental penal para cada una de las entidades } \\
\text { que conforman la Federación ( } 32 \text { entidades y un Distrito } \\
\text { Federal) más un código federal. }\end{array}$ \\
\hline $\begin{array}{l}29 \text { de } \\
\text { diciembre, } \\
2014\end{array}$ & $\begin{array}{c}\text { Ley General } \\
\text { Mecanismos } \\
\text { Alternativos de } \\
\text { Resolución de } \\
\text { Controversias } \\
\text { en Materia } \\
\text { Penal (MASC) }\end{array}$ & $\begin{array}{l}\text { Constituye el marco general que deben tomar en cuenta las } \\
\text { entidades federativas sobre la materia. Establece como } \\
\text { finalidad de los MASC en conflictos penales: propiciar, a } \\
\text { través del diálogo, la solución de las controversias que } \\
\text { surjan entre miembros de la sociedad con motivo de un } \\
\text { hecho delictivo, y a través de procedimientos basados en la } \\
\text { oralidad, la economía procesal y la confidencialidad. } \\
\text { Se reconoce como mecanismos alternativos la mediación, } \\
\text { la conciliación y la junta restaurativa. }\end{array}$ \\
\hline
\end{tabular}

\section{Permanencia de dicotomías constitucionales}

Como ya lo hemos señalado, la reforma constitucional del año 2008 transformó el sistema de impartición de justicia penal. Uno de los argumentos más importantes durante su promoción fue que al aprobarla México se afirmaría como un Estado garantista. Sin embargo, poco se habló de un régimen de excepción que a la par de proposiciones garantistas, también se incluían en la Constitución. Se trataba de disposiciones especiales para la delincuencia organizada que encontraban fundamento en postulados de Jünger Jakobs y la teoría de un derecho penal del enemigo. ${ }^{4}$

De esta manera se elevó a jerarquía constitucional los tratados internacionales en materia de derechos humanos y la presunción de inocencia, al mismo tiempo que se incluyó un catálogo de delitos (cuestionable desde la técnica jurídica), previsiones de restricciones a las garantías y derechos de aquellos que se les relacionara (es decir, ni siquiera que se compruebe su relación) con la delincuencia organizada. Esto significa que con la reforma se incluye a nivel constitucional, el derecho penal de autor así como la aceptación tácita de la presunción de culpabilidad en determinados casos. El peligro es que esta previsión considerada como excepción resulte en ser la regla general, pues como veremos este régimen excepcional se ha ido extendiendo a otros ordenamientos jurídicos nacionales.

\footnotetext{
${ }^{4}$ COAÑA BE, Luis. México: ¿Garantismo o derecho penal del enemigo? México: UBIJUS, 2014. P. 69-100.
} 
Con las reformas constitucionales del año 2011 se dio paso al control difuso de la constitucionalidad por parte de todas los jueces (se superó el control concentrado), el reconocimiento de instrumentos internacionales en materia de derechos humanos con la misma jerarquía que la Constitución Federal y el reconocimiento constitucional en todo tiempo del principio pro persona. ${ }^{5}$ Debería entenderse que el régimen de excepción se debería acotar e incluso, su destino evidente sería la desaparición, ${ }^{6}$ sin embargo, tanto el legislativo como el poder judicial, han continuado afirmando un derecho penal del enemigo. Hoy en día se encuentran vigentes figuras de corte inquisitorial como el arraigo, la prisión preventiva y una tácita presunción de culpabilidad en casos particulares, e incluso la Suprema Corte de Justicia de la Nación ha declarado a varias de ellas como instituciones constitucionales.

\section{Reforzamiento de un Derecho Penal de excepción}

Desde los acontecimientos del 11 de septiembre de 2001 en Estados Unidos, adjudicados a grupos terroristas, en todo el mundo surgió una ola de persecución y castigo de los sujetos que pudieran representar un riesgo. ${ }^{7}$

México resultó influenciado por esta tendencia y adoptó leyes de combate a la criminalidad organizada, sobre todo para evitar el financiamiento de este tipo de actividades. Por ejemplo, la Ley Federal para la Prevención e Identificación de Operaciones con Recursos de Procedencia Ilícita:

“cuyo contenido normativo pretende 'prevenir' conductas de competencia económica que el sistema considera como ilícitas mediante la aplicación de principios de derecho penal del enemigo, tales como la imputación anticipada, la detención por simple sospecha, la reversión de la carga de la prueba, la eliminación del secreto bancario y el otorgamiento de facultades especiales de investigación a la Secretaría de Hacienda y Crédito Público.

Esta ley no hubiera podido formar parte del apartado garantista que contenía nuestra constitución antes de la reforma que sufrió en el año 2008, de hecho, le podemos llamar como una norma que forma parte del Derecho Penal de excepción que se encuentra objetivizado a la luz de la Ley Federal contra la Delincuencia Organizada que fue publicada en el Diario Oficial de nuestro país el 7 de noviembre de $1996^{8}$ y que contiene dentro del catálogo de delitos de alto impacto a las operaciones con recursos de procedencia ilícita, en este caso el artículo 400 bis del Código Penal Federal". ${ }^{9}$

\footnotetext{
5 México. Constitución Política de los Estados Unidos Mexicanos. 11 de junio, 2011. Artículo $1^{\circ}$ constitucional, segundo párrafo.

${ }^{6}$ ALEXY, Robert. Teoría del discurso y derechos humanos; Luis Villar Borda (trad.), 2a ed, Bogotá: Universidad Externado de Colombia. 1995. P. 35.

7 TALAVERA ELGUERA, Pablo. "El derecho procesal del enemigo en la legislación comparada". Revista Justicia y Democracia revista de la Académica de la Magistratura. 2011, núm. 10, Fondo Editorial, Lima, Perú. P. 34- 64

8 Cámara de Diputados [en línea]. México. Legislación Federal. Disponible en http://www.diputados.gob.mx/LeyesBiblio/pdf/101.pdf

${ }^{9}$ PADILLA SANABRIA, Lisbeth Xochitl. "La criminalización del enemigo en el México neoliberal: La ley antilavado". Revista de la Facultad de Derecho. 2013, Vol. 9, Núm. 17, julio-diciembre, UNAM, México. P. $51-52$.
} 
En México no existen conflictos relacionados con el terrorismo. Sin embargo, afectado por la tendencia que los Estados Unidos de Norteamérica agudizaron, el 14 de marzo de 2014 se publicaron en el DOF reformas al artículo 139 del Código Penal Federal, para adicionar las conductas tipificadas como terrorismo. En el tipo penal se incluyó como terrorismo las conductas que "... por cualquier otro medio violento, intencionalmente realice actos en contra de bienes o servicios, ya sea públicos o privados, o bien, en contra de la integridad física, emocional, o la vida de personas, que produzcan alarma, temor o terror en la población o en un grupo o sector de ella, para atentar contra la seguridad nacional o presionar a la autoridad o a un particular, u obligar a éste para que tome una determinación...".

La principal crítica fue que los cambios incluyen términos ambiguos que pueden ser utilizados para criminalizar las protestas sociales.

Otro ejemplo de legislación en la que se extendió el régimen de excepción fue la reforma financiera del año 2013 donde se aprobó la procedencia de arraigo, secuestro de bienes y penas privativas de prisión para deudas de carácter civil. ${ }^{10}$

El régimen de excepción se ha extendido a las legislaturas, donde algunos Estados de la federación, han aprobado leyes que permiten el uso de armas por parte de cuerpos policiacos, para contener manifestaciones (conocidas como ley bala). ${ }^{11}$

Estas prácticas han alcanzado al poder judicial. Es así que la Suprema Corte de Justicia de la Nación, con base en la contradicción de la tesis 422/2013, decidió por mayoría de cuatro votos a uno, que sí es posible embargar parte del salario de un trabajador, si este le debe a un particular, ya sea persona física o moral, en base a una revisión sistemática e integral de la Constitución y de la legislación civil y laboral. ${ }^{12}$

\section{Mayores penas}

En abril de 2014 fue aprobada en el Congreso de la Unión, reformas a la Ley General para Prevenir y Sancionar los Delitos en Materia de Secuestro, por la cual se duplica las penas a secuestradores y que las lleva hasta 140 años de prisión y multas económicas de hasta 24 mil días de salario mínimo vigente.

Se establece en el artículo 9 que quien prive de la libertad a otra persona se le aplicarán de 40 a 80 años de prisión y de mil a cuatro mil días de multa. En el artículo 10 en la fracción II se establecen penas de 50 a 100 años de prisión y de ocho a 16 mil días de multa si los autores son o han sido integrantes de alguna institución de seguridad pública, de

\footnotetext{
${ }^{10}$ ADN Político. ¿Cómo beneficia a los bancos la reforma financiera [en línea]. México: septiembre 2013 [consultado el 3 de mayo, 2015]. Disponible en web http://www.adnpolitico.com/congreso/2013/09/10/conreforma-financiera-posible-arraigo-y-carcel-a-deudores

${ }^{11}$ CNN. La ley bala en Puebla tuvo corta vida pero generó gran polémica [en línea]. México: julio 2014 [consultado el 7 de mayo, 2015]. Disponible en web http://mexico.cnn.com/nacional/2014/07/24/la-ley-balade-puebla-tuvo-corta-vida-pero-genero-una-gran-polemica

${ }^{12}$ SDP Noticias. La SCJN dictamina que el salario sí puede ser embargado por deudas mercantiles y civiles [en línea]. México: abril 2014 [consultado el 7 de junio, 2015]. Disponible en web http://www.sdpnoticias.com/columnas/2014/04/14/la-scjn-dictamina-que-el-salario-si-puede-ser-embargadopor-deudas-mercantiles-y-civiles
} 
procuración o administración de justicia, o de las Fuerzas Armadas Mexicanas, o se ostenten como tales sin serlo. El artículo 11 contempla penas de 80 a 140 años de prisión y multas de 12 a 24 mil días si los autores o partícipes privan de la vida al secuestrado. ${ }^{13}$

Es evidente, que con estas reformas se sigue reforzando el régimen de excepción. Sin embargo, se deja a un lado principios constitucionales como la reinserción social, o bien, lo dispuesto por el artículo 22 constitucional sobre la privación de penas excesivas.

\section{Jerarquía de los tratados internacionales}

La Suprema Corte de Justicia de la Nación (SCJN) es una institución de suma importancia en el diseño del sistema jurídico nacional. Se trata del intérprete último de la Constitución.

Lamentablemente, ha tomado decisiones contrarias a los avances de reformas constitucionales en materia de derechos humanos. El 3 de septiembre de 2013, la SCJN emitió un nuevo criterio jurisprudencial en el que se reconoce que los derechos humanos contenidos en tratados internacionales de los que México es parte, tienen la misma jerarquía que la Constitución, pero si ésta restringe alguno de esos derechos deberá prevalecer el límite establecido en la Carta Suprema.

Las consideraciones de jerarquía dejan de lado los alcances de la reforma de 2011, con argumentos apartados del lenguaje técnico jurídico. Esta decisión fortalece aún más la tendencia a la supresión de límites normativos al poder e incluso contravienen disposiciones internacionales, toda vez que las obligaciones derivadas del derecho internacional "deben ser cumplidas de buena fe y no puede invocarse para su incumplimiento el derecho interno". 14

El artículo 10. constitucional determinaba que las únicas formas de restricción de los derechos que son constitucionalmente válidas se referían a la existencia de un estado de excepción. Ahora se autoriza al legislador y al ejecutivo crear y actuar conforme normas que van más allá de las previsiones constitucionales sobre derechos humanos y que permiten restricciones extraordinarias a derechos humanos. Ello equivale a poder tener estados de excepción informales. Esta desafortunada interpretación del máximo tribunal, da cabida a figuras como el fraude a la ley y a las obligaciones en materia de derechos

\footnotetext{
${ }^{13}$ Periódico La Jornada. Diputados duplican penas por secuestro [en línea]. México: abril 2014 [consultado el 25 de mayo, 2015]. Disponible en .http://www.jornada.unam.mx/ultimas/2014/04/29/diputados-duplicanpenas-por-secuestro-alcanzarian-140-anos-de-carcel-3397.html

14 CORTE INTERAMERICANA DE DERECHOS HUMANOS. Responsabilidad Internacional por Expedición y Aplicación de Leyes Violatorias de la Convención (Arts. 1 y 2 Convención Americana Sobre Derechos Humanos), Opinión Consultiva OC-14/94 del 9 de diciembre de 1994, Serie A No. 14, párr. 35. CONVENCIÓN DE VIENA SOBRE EL DERECHO DE LOS TRATADOS, “Artículo 26: Pacta sunt servanda. Todo tratado en vigor obliga a las partes y debe ser cumplido por ellas de buena fe." Y "Artículo 27. El derecho interno y la observancia de los tratados. Una parte no podrá invocar las disposiciones de su derecho interno como justificación del incumplimiento de un tratado. Esta norma se entenderá sin perjuicio de lo dispuesto en el artículo 46."
} 
humanos, por parte de las mismas autoridades. Con este criterio, la SCJN comete una grave violación al principio constitucional de progresividad de los derechos humanos. ${ }^{15}$

Un peligro adicional a los avances que se habían logrado en materia de reconocimiento y protección de los derechos humanos, lo representan riesgos latentes de contra reformas.

El 5 de marzo de 2013 se presentó en la Cámara de Senadores, una iniciativa para modificar los artículos 1 y 133 de la Constitución, para revertir las reformas hechas en junio de 2011, sobre la jerarquía de tratados internacionales. Propuso una nueva redacción de los artículos 1 y 133, para "establecer con claridad que la Constitución es la norma suprema de nuestro país" y que los tratados internacionales estarán a su nivel únicamente "en aquello que la complementen". 16

Consideramos se trata de una iniciativa regresiva porque restringe el bloque de convencionalidad, en la parte de derechos humanos, válido conforme el actual artículo $1^{\circ}$ constitucional. ${ }^{17}$ El Derecho Internacional de los Derechos Humanos ha tenido importantes avances y su inclusión en los ordenamientos nacionales representa un progreso para la protección de ellos, su efectividad no significa obstáculo alguno a la soberanía, cuando el Estado está comprometido a su defensa.

Como antecedente de la iniciativa en comento, en enero de 2013, una iniciativa en el mismo sentido fue presentada en la Cámara de Diputados.

Las reformas constitucionales en materia de derechos humanos del 2011 fueron un gran logro, es injustificable, que el tema sea revertirla. Los esfuerzos deben centrarse en consolidarla y hacer de su cumplimiento el actuar diario de las autoridades.

Una vinculación directa con las Universidades y las facultades de Derecho puede ayudar a entender a los legisladores que los derechos humanos son el contenido básico de cualquier democracia, acorde con el Derecho Internacional de los Derechos Humanos. Si las democracias sólo se sostienen en un derecho positivo, corren el riesgo de claudicar ante autoritarismos. Los Estados modernos que se afirmen democráticos deben establecer a la dignidad humana - fundamento de los derechos humanos- como eje de sus sistemas jurídicos.

Dejar pasar estos intentos de contra reforma implica dar paso a que "lo que hoy se reconoce como un atributo inherente a la persona, mañana pudiera dejar de serlo por una decisión gubernamental". 18

\footnotetext{
15 El principio de progresividad establece la obligación para el Estado de generar una mayor y mejor protección y garantía de los derechos humanos para lograr una constante evolución y bajo ninguna justificación un retroceso.

${ }^{16}$ Senado de la República, Gaceta Parlamentaria [en línea]. México: marzo 2013 [consultado el 28 de junio 2015]. Disponible en http://www.senado.gob.mx/?ver=sp\&mn=2\&sm=2\&id=39664

${ }^{17}$ Con las responsabilidades jurídicas que su desconocimiento representaría, pues como hemos mencionado México ha ratificado la competencia de la Corte Interamericana de Derechos Humanos, y en el cumplimiento de los compromisos internacionales no puede argumentar su derecho interno.

${ }^{18}$ NIKKEN, Pedro. "El Derecho Internacional de los Derechos Humanos". Revista de la Facultad de Ciencias Jurídicas y Políticas de la Universidad Central de Venezuela. 1989, núm. 72, Caracas, p. 44. NIKKEN, Pedro. En defensa de la persona humana. Caracas, Editorial Jurídica Venezolana, 1988. p. 32.
} 


\section{El Derecho como norma, como hecho y como valor}

La ciencia jurídica, como ciencia social, tiene un objeto de estudio en el cual interviene la voluntad del ser humano que orienta su conducta hacia el cumplimiento de fines. El derecho como ciencia tiene la función de describir los hechos, explicarlos, analizarlos e incluso condicionarlos. ${ }^{19} \mathrm{El}$ observador es simultáneamente objeto de estudio. Al entender esto, nos alejamos del postulado positivista filosófico según el cual el investigador social toma distancia del objeto de estudio para lograr objetividad.

"La interpretación del Derecho se entiende como cualquier técnica de aproximación al fenómeno jurídico en su realidad histórica, humana y social, para los aplicadores del Derecho. [...] El medio de aproximación no es más que la utilización de la razón [...]." ${ }^{, 20} \mathrm{El}$ investigador que tenga como objeto de estudio al derecho, puede acercarse a él como hecho, como norma o como valor. ${ }^{21}$

Para el Doctor Jorge Witker las herramientas metodológicas que se aplican al estudio del Derecho dependen del enfoque hacia nuestro objeto de estudio: ${ }^{22}$

Investigación dogmática (documental):

- Exegético

- Sistemático

- Sociológico

Investigación empírica:

- Encuesta. Consiste en recopilar opiniones sobre un hecho relevante para el derecho.

- Investigación de campo. Consiste en observar el funcionamiento de una disposición normativa en una comunidad específica.

- Estudio de caso. Consiste en la observación de la aplicación del ordenamiento jurídico a un hecho específico y cómo el contexto influye. ${ }^{23}$

- Experimento social. Recreación de condiciones en un ambiente controlado.

- Entrevista. Recopilación de opiniones a sujetos específicos respecto al funcionamiento de disposiciones jurídicas y/o hechos determinados.

19 Mientras la Filosofía Jurídica indaga los fundamentos y las causas primeras del conocimiento jurídico, la dogmática jurídica tiene como objeto al derecho positivo. Finalmente, se debe distinguir de las anteriores la acepción del término Derecho para el conjunto sistemático de normas jurídicas creadas por el órgano competente mediante los procesos jurídicamente válidos. VILLORO TORANZO, Miguel. Teoría General del Derecho. 6a. Ed. México: Porrúa, 1989. P. 7.

${ }^{20}$ WITKER VELASQUEZ, Jorge A. La investigación jurídica. México: UNAM-Instituto de Investigaciones Jurídicas, 2009. P. 19.

${ }^{21}$ DEL VECCHIO Giorgio. Filosofía del Derecho. México: Porrúa. 1997. Pp. 34 y ss.

${ }^{22}$ LÓPEZ DURÁN, Rosalío. Metodología de la investigación jurídico documental. 2a . Edición. México: Ediciones del autor. 2008. P. 7.

${ }^{23}$ SERNA DE LA GARZA, José María (2004). “Apuntes sobre las opciones de cambio en la metodología de la enseñanza del Derecho en México”. Boletín Mexicano de Derecho Comparado. 2004. Nueva serie, año XXXVII, No 111, septiembre - diciembre. México: IIJ-UNAM. P. 1047 - 1082. 


\section{Planificación de la enseñanza}

La responsabilidad es un valor que debe practicarse durante la enseñanza. "el aprendizaje debe planificarse para que cada persona se aproxime al máximo a las metas de empleo óptimo de sus capacidades, disfrute de su vida e integración con su medio físico y social. [...] la enseñanza planificada trata de contribuir a que cada persona se desarrolle tan complejamente como le sea posible, y en su propio sentido. [...] la enseñanza planificada puede afectar enormemente el desarrollo del individuo como persona." 24

Algunos principios de aprendizaje son:

- Contigüidad. Principio que se basa en el estímulo respuesta, para el cual la acción es fundamental. El estímulo debe presentarse en proximidad temporal.

- Repetición. La dinámica-estimulo respuesta deben suceder en más de una ocasión.

- Reforzamiento. Estimulo positivo ante las conductas deseadas y respuesta negativa ante las respuestas no deseadas.

Factores externos e internos que afectan el proceso de enseñanza-aprendizaje: ${ }^{25}$

1. Factores externos:

- Contigüidad (orden temporal de condiciones)

- Repetición

- Reforzamiento

2. Factores internos

- Información objetiva

- Capacidades intelectuales (recordarlas a partir del aprendizaje previo)

- Estrategias (inducidas o autoproducidas a partir de a práctica previa)

\section{La vinculación como técnica para la enseñanza y aprendizaje del Derecho}

El escenario descrito en apartados anteriores, más allá de percibirse como un obstáculo en la formación de los futuros profesionales jurídicos, representa extensas áreas de oportunidad. El desarrollo de la realidad del ser humano, tan acelerada en la mayoría de los ámbitos, es el campo perfecto para crear sinergias entre diversos actores sociales.

Para la realidad jurídica, ubicada entre los contextos fáctico, normativo y axiológico, un concepto toma protagonismo y se convierte en clave estratégica para la enseñanza y aprendizaje del Derecho como objeto de naturaleza dinámica: la vinculación.

El aprendizaje de conocimiento intelectual conduce a una competencia práctica. Las capacidades intelectuales son la base de actitudes necesarias para el análisis y conocimiento de un objeto específico, sin embargo, por sí solas no proporcionan estrategias suficientes para un aprendizaje autodidacta. Una habilidad intelectual se relaciona con una actividad

\footnotetext{
${ }^{24}$ GAGNÉ, Robert M. y BRIGGS, Leslie J. La planificación de la enseñanza. Sus principios. México: Trillas. 1979. P. 14 y 15.

${ }^{25}$ Ibíd. p. 21.
} 
humana, con algo que el estudiante puede hacer. No se puede transmitir por instrucciones, para recordarse debe haberse practicando antes ${ }^{26}$ en aplicación de principios del aprendizaje (contigüidad, repetición y reforzamiento). Estudiar al Derecho desde el enfoque teórico es fundamental, no obstante la adquisición de aptitudes es primordial para un desarrollo profesional, y en la medida de una mayor influencia de factores externos e internos positivos se lograra un mayor entendimiento del Derecho como objeto de estudio en creación y modificación constante.

Consideramos que vincular el Derecho que se enseña en el aula, con el Derecho que se practica en el devenir diario (desde el interior de las instituciones), permite una profesionalización de los alumnos a través del desarrollo de competencias, al mismo tiempo que fortalece - y en algunos casos, donde se carece por completo, proporciona - un eje al sistema jurídico, proporciona congruencia, evita dicotomías, fortalece la gobernabilidad, da vigencia al estado de derecho y consolida un Estado democrático.

En síntesis, nosotros proponemos la vinculación como técnica para la enseñanza y aprendizaje efectivos del Derecho. Vale la pena aclarar que en esta investigación, al hablar de una técnica de enseñanza, nos referimos a todo procedimiento adoptado en la orientación de las actividades del docente y del alumno durante el proceso enseñanza - aprendizaje. ${ }^{27}$

Como se mencionó en la parte introductoria, nos enfocamos en el poder legislativo por ser el órgano del que emanan normas en su sentido formal y material. Sin embargo, la intención es que esta técnica se extienda a otras instituciones y órganos públicos.

A continuación se desarrolla la propuesta.

\section{Propuesta: La vinculación como técnica para la enseñanza y aprendizaje del Derecho.}

Consiste en un procedimiento de enseñanza-aprendizaje, en el cual el estudiante de Derecho se encuentra en contacto y vinculación directa con actores del poder legislativo.

El estudiante adquiere protagonismo en una dinámica autodidacta.

Por su parte, el docente cumple dos funciones primordiales, por un lado continúa con la enseñanza de la dogmática jurídica y los fundamentos de la ciencia del Derecho (proceso en el cual interviene una pluralidad de técnicas e instrumentos de enseñanza), y por otro, actúa a manera de asesor, quien orienta durante la vinculación.

\section{Etapas:}

Consideramos dos grandes etapas. la razón de la división responde principalmente a: 1) lograr una implementación en los planes de estudio conciliadora con las prácticas actuales en las universidades, y 2) conseguir una transición gradual y progresiva con los estudiantes

\footnotetext{
${ }^{26}$ Ibíd. Pp. 20, 22 y 23.

${ }^{27}$ Sobre el particular, se recomienda consultar ANDRADE ESCOBAR, Angelina (et al.). Manual. Técnicas e instrumentos para facilitar la evaluación del aprendizaje. México: Centro de Enseñanza y Técnica Superior, 2010. P. 5.
} 
de derecho de generaciones anteriores, que cursan planes de estudio vigentes, así como las generaciones que recién se integran a la carrera.

Las etapas son:

1. Talleres. Consiste en la formación de grupos de trabajo, como actividad extra curricular, en la que asesores jurídico-legislativos (muchos de ellos egresados de la misma Universidad), de manera rotativa e itinerante, asistan a sesiones semanales con estos grupos de estudiantes. Se trata de una sesión de interacción y diálogo directo. El objeto es abordar dos ejes temáticos principales:

a) Técnica legislativa. En este apartado, se desarrollarán exposición de experiencias y aprendizajes relacionados con los temas de Derecho Parlamentario. Se estudiarán con especial énfasis, elementos de técnica legislativa relacionados con el procedimiento, las reglas y normas para la creación y modificación de leyes.

Los alumnos aprenderán de la práctica parlamentaria diaria en su etapa formalizada, como por ejemplo los elementos de una iniciativa, las partes que integran un dictamen de ley, el desarrollo del proceso legislativo dentro de comisiones, trabajo previo a la discusión en pleno, intervención de legisladores durante la discusión de los asuntos legislativos, Ley Orgánica del Congreso General, reglamento de cada una de las Cámaras, etc. El objetivo es que los alumnos identifiquen cómo funciona y se aplica, el marco normativo, al proceso y procedimientos legislativos.

b) Prácticas y acuerdos legislativos. Bajo esta temática, los expositores invitados exponen sobre el desarrollo diario de la tarea legislativa, que es donde se presenta situaciones que deben resolverse (aunque no haya disposición expresa que las contemple) en el ejercicio de esta labor. Se trata de acciones que instrumentan los integrantes de los congresos para subsanar vacíos o lagunas de ley, así como para eficientar el trabajo legislativo. $^{28}$

Las exposiciones consistirán en compartir vivencias representativas ${ }^{29}$ de la tarea legislativa, donde hayan, por ejemplo, intervenido factores no jurídicos en el diseño de las leyes. Se trata de compartir con los estudiantes experiencia sobre el ejercicio de la práctica parlamentaria, el cómo se han logrado acuerdos, el contexto en el cual se han dado las negociaciones. Incluso, esta etapa puede incluir una introducción a los procesos de cabildeo desde el poder legislativo (sujetos, función, estrategias, metodología, implicaciones). El objetivo es identificar y analizar la participación de diversos factores sociales, económicos, políticos, culturales e incluso psicológicos ${ }^{30}$, en el diseño o modificación de una norma jurídica.

\footnotetext{
${ }^{28}$ PEDROZA DE LA LLAVE, Susana Thalía. El Congreso de la Unión. Integración y regulación. México: Instituto de Investigaciones Jurídicas - UNAM. 1997. P. 193-214. Sistema de Información Legislativa (SIL). México. Ley Orgánica del Congreso General. 23 de octubre, 2006. Artículo 40, 50, 90 y 102.

${ }^{29}$ Es decir, experiencias que hayan sido trascendentales para los expositores y de las cuales se pueda obtener algún aprendizaje para la formación del estudiante y futuro profesional.

${ }^{30}$ El factor psicológico se presenta en situaciones como una negociación política o en las estrategias de comunicación y los procesos de debate.
} 
2. Clases. Se trata de una etapa que se implementará en un momento avanzado del proyecto. Esto no significa que la implementación de esta técnica en su totalidad requiera de un lapso prolongado.

La modificación de los planes de estudio implica, en algunas ocasiones, procesos de consulta prolongados, poca confianza en sus beneficios y oposición justificada $\mathrm{o}$ injustificada, de algunos sectores.

Es decir, una vez que se haya logrado el interés entre alumnos y autoridades de la Universidad, se propondría la inclusión de la dinámica de los talleres en las clases optativas con valor curricular. Al ser evidente las implicaciones positivas que la etapa de talleres generó para estudiantes, universidad y para el propio poder legislativo, habrá menor resistencia a modificar los planes de estudio.

Considerar las clases como una segunda fase, representa ciertas ventajas. La principal es conseguir una implementación armónica, pacífica y eficiente. Es decir, lograr una implementación de la metodología propuesta en el menor tiempo posible, y al mismo tiempo, se asegurarán los propósitos planteados en el inicio.

En la primera fase consideramos solo la participación de asesores, toda vez que su agenda permite más flexibilidad de horario, pero conforme a que el proyecto se conozca, obtenga mayor difusión y cuente con el respaldo oficial de autoridades de la universidad, se incorporarán estrategias didácticas — a cargo de Senadores y Diputados —, tales como ponencias, conferencias, conferencia magistral, figura de profesor invitado.

\section{Objetivo a largo plazo:}

Lograr un sistema de vinculación Facultad-Poderes de la Unión- Instituciones públicas

- Vinculación con el Poder Ejecutivo.

- Vinculación con el Poder Legislativo

- Vinculación con el Poder Judicial

- Vinculación con Instituciones Públicas

Una vez formalizarse la metodología de enseñanza-aprendizaje a través de vinculación con el poder legislativo, el objetivo inmediato será replicar el modelo en otras instituciones. Al mismo tiempo, se propone como parte de la metodología sugerida, diseñar un eje transversal común (semejante a lo que se conoce como tronco común en los sistemas de estudio) para todas las áreas de vinculación institucional. Se trata de incluir la enseñanza de técnicas y herramientas útiles en la interacción y desenvolvimiento social, habilidades necesarias para todo profesionista, por ejemplo:

- Estrategias de comunicación.

- Comunicación asertiva.

- Mediación

- Cultura general (lograr que los abogados retomen su presencia como poseedores de un amplio bagaje en cultural en arte, historia nacional y universal, así como en otras áreas del conocimiento). 


\section{Ventajas de la propuesta}

1. El desarrollo de la propuesta en dos grandes etapas, permite su implementación a corto plazo, porque la primera fase de talleres, se realizará sin necesidad de llevar a cabo tardados trámites hacia dentro de la universidad. La propuesta consiste en iniciar el proyecto con una mecánica informal pero útil. Los talleres son una especie de "interacciones informales o charlas entre colegas", donde el aprendizaje es mutuo, en un ambiente relajado y autodidacta, sin evaluaciones o tareas, los únicos compromisos son los que cada asistente se fije para su desarrollo personal y profesional, y dependerán de la motivación y entusiasmo que cada uno posea.

2. Para los estudiantes en derecho esta interacción con profesionales que ya ejercen la carrera, representa varios beneficios, los más significativos para nosotros, son:

a. Las propuestas de tesis llegarán al conocimiento de actores del legislativo, ejecutivo y judicial. Aquellas que proponen modificaciones al sistema normativo, por ejemplo, y que se sustentan en una investigación seria, podrían llevarse a la realidad, y dejar de ser solo un ejemplar más en los estantes de la biblioteca. Lo mismo sucede con los estudios y reflexiones que se realicen sobre la práctica de los poderes ejecutivo y judicial. Los esfuerzos destinados a la tarea de investigación, serán más que solo un requisito para obtener el grado, podrán cobrar operatividad y materializar las propuestas de los estudiantes.

b. Vinculación directamente con el ámbito gubernamental y así contar con los contactos y referencias que permitan el acceso a oportunidades laborales en el campo jurídico.

c. Ampliación de horizontes. Percibir, por parte del estudiante, que lo que estudia tiene una aplicación real y que puede coadyuvar a mejores prácticas. Adicionalmente, la interacción directa con la realidad de las instituciones, motiva al alumno para ampliar y complementar los conocimientos teóricos, con periódicos y otras fuentes hemerográficas. El alumno desarrollará mayor conciencia sobre su situación y la situación fuera de las aulas (en su contexto social, familiar, en su país).

d. Conocimientos actualizados. El contacto con los agentes responsables de los cambios jurídicos, de las interpretaciones normativas, y de la misma práctica del derecho, genera alumnos conocedores de las propuestas legislativas, así como de los criterios judiciales y del ejecutivo. Con ello no tendrían que pasar largos años, incluso generaciones enteras, para la actualización de las asignaturas. Pese a los desfasados e incluso obsoletos planes de estudio, las universidades lograrían egresados actualizados en la práctica del derecho.

3. Para los poderes de la Unión, estar en vinculación con los estudiantes en derecho y en general con la academia, representa los siguientes beneficios:

a. Conocer y por tanto incluir postulados filosóficos del Derecho en el diseño normativo, y con ello se promueve una mejor producción y calidad legislativa con impacto directo en el desarrollo nacional. 
b. Al definir e incluir elementos filosóficos, generados con las investigaciones y reflexiones de los estudiantes, en la práctica institucional podrán lograrse políticas públicas con rumbo, continuidad y congruencia, toda vez que se retroalimentarán de estudiantes dedicados al análisis de temas específicos.

\section{Conclusiones}

1. Es tarea de todo profesional del Derecho actualizarse, desarrollar sus conocimientos y competencias profesionales. Esta labor debe iniciar como hábito y responsabilidad, desde su paso por las aulas de las facultades y escuelas de derecho.

2. Un reto prioritario para las instituciones de educación superior es lograr egresados capaces de enfrentar retos que una sociedad dinámica les presenta.

3. Mantener actualizados los planes y programas de estudio también constituye un reto para las instituciones de educación superior. El principal elemento a considerar son los constantes cambios a las estructuras jurídico nacionales. La pretensión no es buscar un cambio a los programas ante cada modificación legal, lo conveniente es solicitar las adecuaciones cuando se reestructuran elementos base del sistema jurídico nacional, es decir solo en aquellos casos en que los paradigmas cambien.

4. Universidades y facultades, en su labor de formación de profesionales con competencias, aptitudes y valores, deben aprovechar su calidad de instituciones para lograr la vinculación con otras instituciones públicas gubernamentales para propiciar el contacto de sus estudiantes con el derecho como fenómeno, norma y valor.

5. México se encuentra en un momento de implementación de importantes reformas en materia de derechos humanos, resultado de loables y constantes esfuerzos. Pese a ello, los riesgos de retroceso son latentes. Una vinculación entre Universidades y Facultades de Derecho con el Poder Legislativo, coadyuva a evitar una estrategia política improvisada o mal intencionada que además resulta violatoria de compromisos internacionales en materia de derechos humanos.

6. Para consolidar la democracia y el Estado de Derecho como realidad y no solo como concepto, resulta imprescindible el contacto permanente entre los sectores donde se estudia el derecho, donde se crea el derecho y con los sectores desde donde se toman decisiones públicas.

7. Mediante la vinculación se puede mantener actualizada la materia que se enseña, sin necesidad de esperar años para modificar un plan de estudio.

8. La vinculación entre facultades e instituciones públicas gubernamentales permite a los alumnos familiarizarse con la realidad en la que al terminar la carrera o incluso antes, participarán como operadores, creadores, investigadores o actores jurídicos.

9. La vinculación entre la academia con las instituciones públicas dota a los alumnos, con el conocimiento técnico y científico que respalde sus decisiones como profesionales. 
10. Contar con este conocimiento técnico científico ayuda a evitar dicotomías en el sistema jurídico y coadyuva a lograr unidad, sistematicidad y congruencia.

11. Por las ventajas que representa para los involucrados directamente, y para la sociedad en general, la vinculación entre facultades y escuelas debe establecerse como una técnica de enseñanza y aprendizaje del Derecho.

\section{Referencias bibliográficas}

ALEXY, Robert. Teoría del discurso y derechos humanos. Luis Villar Borda (trad.), $2^{\mathrm{a}}$ ed., Bogotá: Universidad Externado de Colombia. 1995. 136 p.

COAÑA BE, Luís. México: ¿Garantismo o derecho penal del enemigo? México: UBIJUS, 2014. P. 69-100.

DEL VECCHIO Giorgio. Filosofía del Derecho. Tomo I. México: Porrúa. 1997. 559 p.

RECASENZ SICHES, Luis. Estudios de Filosofía del Derecho. Editorial Bosh. Barcelona, 1936.

GAGNÉ, Robert M. y BRIGGS, Leslie J. La planificación de la enseñanza. Sus principios. México: Trillas. 1979. 287 pp.

LÓPEZ DURÁN, Rosalío. Metodología de la investigación jurídico documental. 2a . Edición. México: Ediciones del autor. 2008. 90 p.

NIKKEN, Pedro. El derecho internacional de los derechos humanos. En Revista de la Facultad de Ciencias Jurídicas y Políticas de la Universidad Central de Venezuela. 1989, núm. 72, Caracas.

NIKKEN, Pedro. En defensa de la persona humana. Caracas: Editorial Jurídica Venezolana, 1988.

PADILLA SANABRIA, Lisbeth Xochitl. La criminalización del enemigo en el México neoliberal: La ley antilavado. Revista de la Facultad de Derecho. 2013, Vol. 9, Núm. 17, julio-diciembre, UNAM, México. P. $51-72$.

PEDROZA DE LA LLAVE, Susana Thalía. El Congreso de la Unión. Integración y regulación. México: Instituto de Investigaciones Jurídicas - UNAM. 1997. 263 p.

SERNA DE LA GARZA, José María. Apuntes sobre las opciones de cambio en la metodología de la enseñanza del Derecho en México. Boletín Mexicano de Derecho Comparado. 2004. Nueva serie, año XXXVII, núm. 111, septiembre - diciembre. IIJUNAM. México. P. 1047 - 1082.

ANDRADE ESCOBAR, Angelina (et al.). Manual. Técnicas e instrumentos para facilitar la evaluación del aprendizaje. México: Centro de Enseñanza y Técnica Superior, 2010. 60 p. 
TALAVERA ELGUERA, Pablo. El derecho procesal del enemigo en la legislación comparada. Revista Justicia y Democracia revista de la Académica de la Magistratura. 2011, núm. 10, Fondo Editorial, Lima, Perú. P. 34- 64

VILLORO TORANZO, Miguel. Teoría General del Derecho. 6ª ed. México: Porrúa, 2009. $169 \mathrm{p}$.

WITKER VELASQUEZ, Jorge A. La investigación jurídica. México: UNAM-Instituto de Investigaciones Jurídicas, 2009. 185 p.

\section{Fuentes electrónicas}

ADN Político. ¿Cómo beneficia a los bancos la reforma financiera [en línea]. México: septiembre 2013 [consultado el 3 de mayo, 2015]. Disponible en http://www.adnpolitico.com/congreso/2013/09/10/con-reforma-financiera-posible-arraigoy-carcel-a-deudores

Cámara de Diputados. México. Legislación Federal. Disponible en http://www.diputados.gob.mx/LeyesBiblio/pdf/101.pdf

CNN. La ley bala en Puebla tuvo corta vida pero generó gran polémica [en línea]. México: julio 2014 [consultado el 7 de mayo, 2015]. Disponible en http://mexico.cnn.com/nacional/2014/07/24/la-ley-bala-de-puebla-tuvo-corta-vida-perogenero-una-gran-polemica

Periódico La Jornada. Diputados duplican penas por secuestro [en línea]. México: abril 2014 [consultado el 25 de mayo, 2015]. Disponible en web http://www.jornada.unam.mx/ultimas/2014/04/29/diputados-duplican-penas-por-secuestroalcanzarian-140-anos-de-carcel-3397.html

SDP Noticias. La SCJN dictamina que el salario sí puede ser embargado por deudas mercantiles y civiles [en línea]. México: abril 2014 [consultado el 7 de junio, 2015]. Disponible en http://www.sdpnoticias.com/columnas/2014/04/14/la-scjn-dictamina-que-elsalario-si-puede-ser-embargado-por-deudas-mercantiles-y-civiles

Senado de la República, Gaceta Parlamentaria [en línea]. México: marzo 2013. Disponible en http://www.senado.gob.mx/?ver=sp\&mn=2\&sm=2\&id=39664

Sistema de Información Legislativa (SIL). México.

\section{Legislación}

México. Constitución Política de los Estados Unidos Mexicanos. 11 de junio, 2011. Artículo $1^{\circ}$ constitucional, segundo párrafo. P. 2.

CONVENCIÓN DE VIENA SOBRE EL DERECHO DE LOS TRATADOS, “Artículo 26: Pacta sunt servanda. Todo tratado en vigor obliga a las partes y debe ser cumplido por ellas de buena fe." Y "Artículo 27. El derecho interno y la observancia de los tratados. Una parte no podrá invocar las disposiciones de su derecho interno como justificación del 
incumplimiento de un tratado. Esta norma se entenderá sin perjuicio de lo dispuesto en el artículo 46."

CORTE INTERAMERICANA DE DERECHOS HUMANOS. Responsabilidad Internacional por Expedición y Aplicación de Leyes Violatorias de la Convención (Arts. 1 y 2 Convención Americana Sobre Derechos Humanos), Opinión Consultiva OC-14/94 del 9 de diciembre de 1994, Serie A No. 14, párr. 35.

México. Ley Orgánica del Congreso General. 23 de octubre, 2006. 